\title{
Circular hook-shaped wireless USB dongle antenna with an open stub
}

\author{
Seong Jae Jeong and Keum Cheol Hwang ${ }^{\text {a) }}$ \\ Division of Electronics and Electrical Engineering, Dongguk University-Seoul, \\ Seoul, 100-715, Korea \\ a)kchwang@dongguk.edu
}

\begin{abstract}
This research presents the design of a novel pentaband planar antenna for wireless USB dongle applications. The main radiator is comprised of a circular hook-shaped patch and a monopole stub to achieve dual-wideband operation. This novel pentaband antenna measures only $10 \times 49.5 \times 0.8 \mathrm{~mm}^{3}$. The measured $10 \mathrm{~dB}$ return loss bandwidths of the fabricated antenna are $26.2 \%(2.29-2.98 \mathrm{GHz})$ and 21.5\% (5.12-6.35 GHz), thereby supporting WiBro, Bluetooth, WLAN, WiMAX, and S-DMB (Satellite Digital Multimedia Broadcast) services. The gain and radiation efficiency of the antenna are also discussed.
\end{abstract}

Keywords: internal antenna, hook-shaped patch, wireless USB dongle

Classification: Microwave and millimeter wave devices, circuits, and systems

\section{References}

[1] Certified wireless USB, [online] http://www.intel.com/technology/ comms/wusb/

[2] D. D. Krishna, M. Gopikrishna, C. K. Aanandan, P. Mohanan, and K. Vasudevan, "Ultra-wideband slot antenna for wireless USB dongle applications," Electron. Lett., vol. 44, no. 18, pp. 1057-1058, Aug. 2008.

[3] R. Bayderkhani and G. R. Dadashzadeh, "Printed wideband CPW-fed slot antenna with high polarization purity," IEICE Electron. Express, vol. 7, no. 4, pp. 295-301, Feb. 2010.

[4] J. Jung, H. Lee, and Y. Lim, "Broadband E-shaped monopole antenna for USB dongle application," Microw. Opt. Technol. Lett., vol. 51, no. 10, pp. 2387-2390, Oct. 2009.

[5] W.-S. Chen and K.-Y. Ku, "A Microstrip-fed monopole antenna for WLAN USB applications," Microw. J., vol. 51, no. 3, pp. 104-107, March 2008.

[6] Y. Yu and J. Choi, "Compact internal inverted-F antenna for USB dongle applications," Electron. Lett., vol. 45, no. 2, pp. 92-93, Jan. 2009.

[7] S. J. Jeong and K. C. Hwang, "Design of an internal Hook-shaped antenna for multiband wireless USB dongle applications," Proc. IEEK Summer Conference, Jeju, Korea, pp. 900-901, June 2010. 
[8] Ansoft High Frequency Structure Simulator (HFSS), ver. 10, [online] http://www.ansoft.com

\section{Introduction}

Universal serial bus (USB) technology was developed to replace conventional serial and parallel data ports. The USB 2.0 specification provides a simple plug-and-play function and a high data transfer rate of $480 \mathrm{Mbps}$. Based on the success of wired USB, wireless USB technology was introduced by the USB implementers forum (USB IF) to provide the convenience of highspeed wireless technology for consumers [1]. Consequently, the demand for portable, multiband wireless USB dongle devices has grown significantly. Furthermore, these wireless USB dongles require miniaturized antennas that not only can be integrated into a dongle board but can also provide a desirable level of electrical performance. Based on a coplanar waveguide feed, an ultra-wideband (UWB) printed slot antenna was presented in $[2,3]$. A broadband E-shaped antenna for USB dongle application was proposed to cover UMTS, WiBro, WLAN, and S-DMB [4]. Monopole and inverted-F type USB dongle antennas have been also investigated for multiband wireless applications $[5,6,7]$. In this study, a novel circular hook-shaped antenna with a compact width was proposed. By properly adjusting the shape of the circular hook patch and monopole stub, the dual-wideband design of the proposed antenna was achieved. The entire dimension of the proposed antenna including the ground plane is as small as $10 \times 49.5 \times 0.8 \mathrm{~mm}^{3}$, which ensures that the antenna can be incorporated into wireless USB dongles having a compact width. The design and optimization of the antenna were completed using Ansoft HFSS based on the finite element method [8]. Details of the antenna design, fabrication, and experimental results are presented and discussed in the subsequent sections.

\section{Antenna design}

Fig. 1(a) shows the configuration of the proposed dual-wideband planar monopole antenna printed on the top portion of a wireless USB circuit board. The system ground plane was chosen to have a dimension of $10 \times 40 \mathrm{~mm}^{2}$, which corresponds to the dimensions of some practical compact USB dongles. The main radiator has a simple structure with a circular hook-shaped patch and a monopole stub for dual-wideband operation. The curves of the outer and inner $\left(C_{1}\right.$ and $\left.C_{2}\right)$ edges of the circular hook-shaped patch are initially designed as arcs with different lengths. Therefore, the design equations are given as

$$
\begin{aligned}
& C_{1}:(x-a)^{2}+(y-b)^{2}=r^{2} \\
& C_{2}:\left(x-a^{\prime}\right)^{2}+\left(y-b^{\prime}\right)^{2}=r^{\prime 2}
\end{aligned}
$$




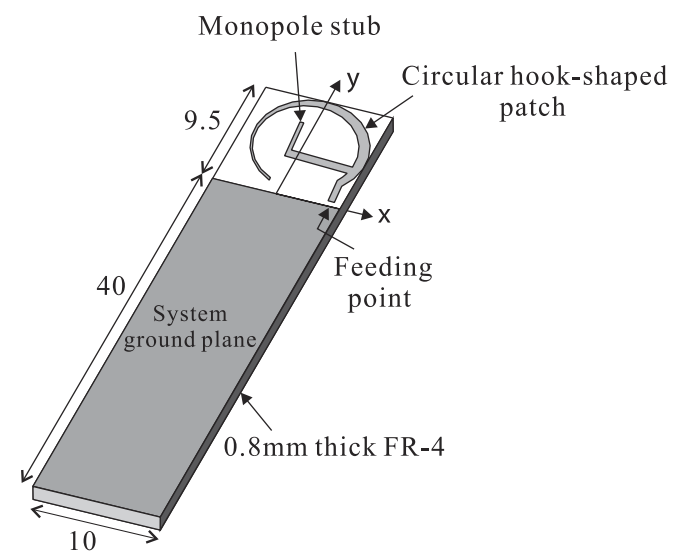

(a)

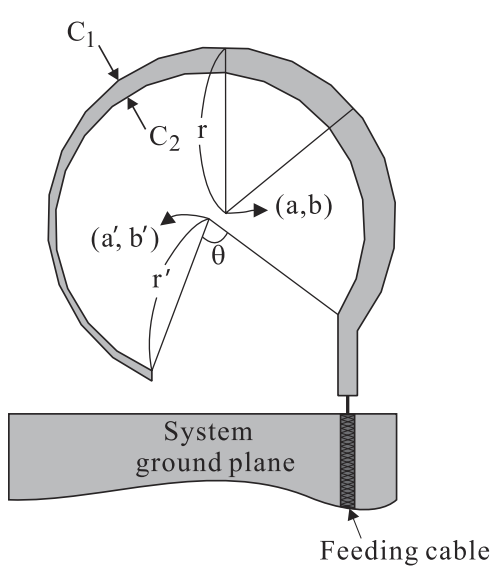

(b)

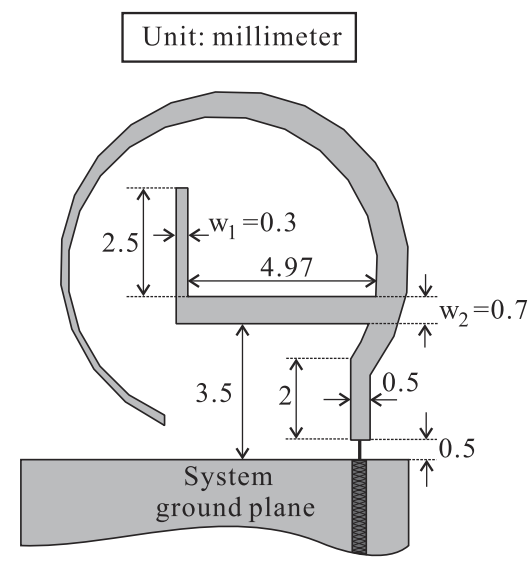

(c)

Fig. 1. (a) Configuration of the proposed antenna (b) geometry of a circular hook-shaped patch (c) optimum dimensions for radiating elements.

where $(a, b)$ and $\left(a^{\prime}, b^{\prime}\right)$ are the central points of the outer circle and the inner circle, respectively; and $r$ and $r^{\prime}$ are the radii of the circles. Note that these characteristic formulas are valid for $2 \pi-\theta$ (See Fig. 1(b)). The lower resonant frequency of the proposed antenna is mainly controlled by the hook-shaped patch. In this antenna design, the total length of the hook-shaped patch is about $25 \mathrm{~mm}$, which correspond to a quarter of the wavelength at $3 \mathrm{GHz}$. The simulated reflection losses of the hook-shaped patch for various design parameters are shown in Fig. 2. Enhanced, wideband antenna matching at the lower resonant band can be achieved by changing central point of the inner circle $\left(a^{\prime}, b^{\prime}\right)$, as shown in Figs. 2(a) and 2(b). The effect of angle $\theta$ on the reflection loss was also studied, and this result is shown in Fig. 2(c). As the angle $\theta$ increases, the resonant frequencies shift slightly to a lower frequency. Although the circular hook-shaped patch resonates at the $2.5 \mathrm{GHz}$ ISM band, a folded monopole stub was included in the hook-shaped patch to generate an additional resonance frequency at the upper frequency band near 5.5 GHz. The total length of the monopole stub is about $7.5 \mathrm{~mm}$. The width parameters of the vertical and horizontal strips of the monopole stub ( $w_{1}$ and $w_{2}$ ) were utilized to enhance the impedance matching at the upper resonant 


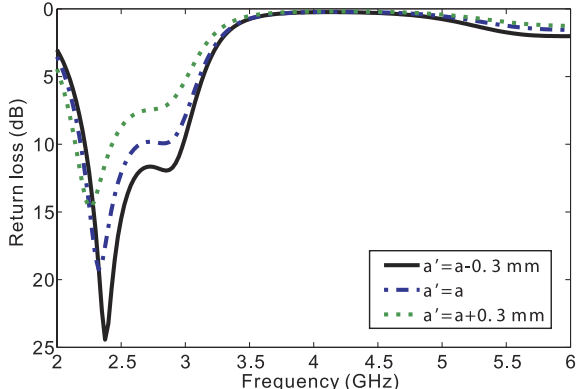

(a)

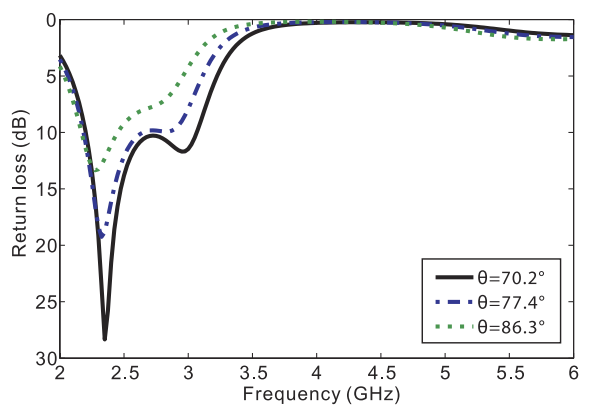

(c)

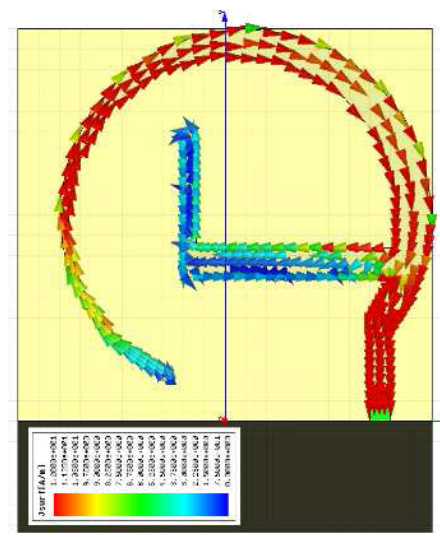

(e)

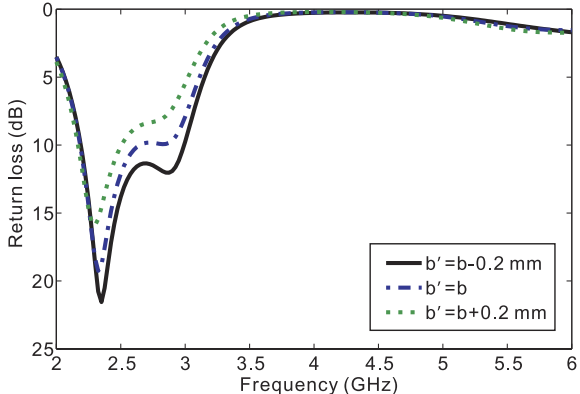

(b)

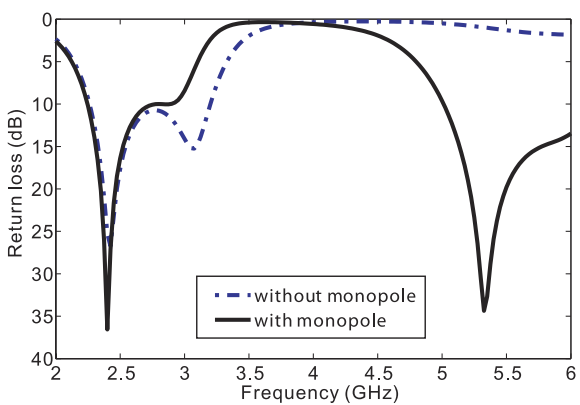

(d)

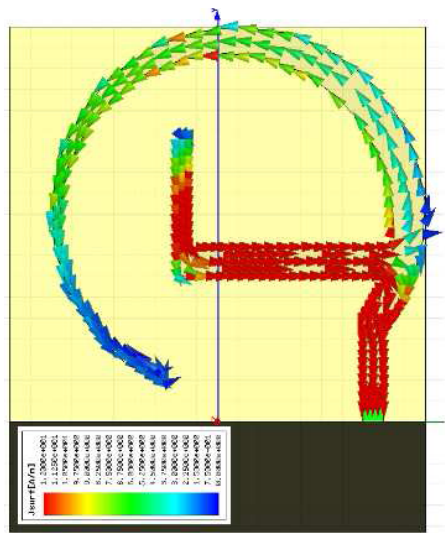

(f)

Fig. 2. Simulated return losses of the circular hookshaped patch as a function of (a) $a^{\prime}$ (b) $b^{\prime}$ (c) $\theta$ (d) effect of a monopole element on return loss (e) simulated surface current distribution at $2.5 \mathrm{GHz}$ (f) simulated surface current distribution at $5.5 \mathrm{GHz}$.

frequency. When both the hook-shaped patch and the monopole stub are combined, the second resonant frequency of the hook-shaped patch shifts to a lower frequency due to the mutual coupling between them (See Fig. 2(d)). Therefore, the resonant bandwidth of the proposed antenna can support specific wireless services, including WiBro, Bluetooth, WLAN, WiMAX, and SDMB. This operational principle can be confirmed in the simulated current distributions shown in Figs. 2(e) and 2(f). At the lower resonant frequency, the surface current is concentrated on the hook-shaped patch, whereas the surface current is mainly distributed on the monopole stub at the upper resonant frequency. The optimized design parameters for the proposed antenna 


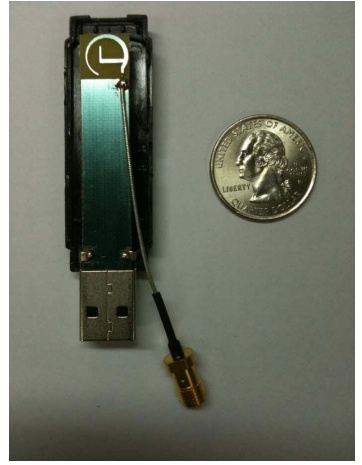

(a)

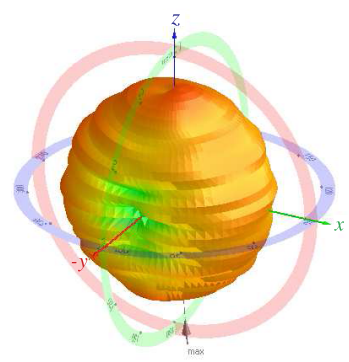

(c)

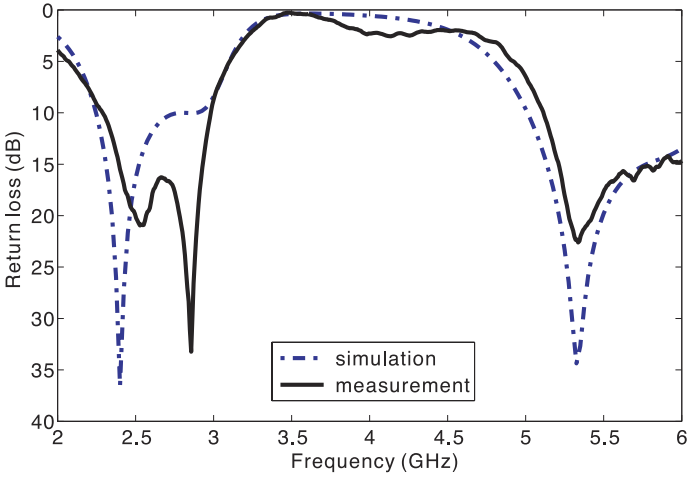

(b)
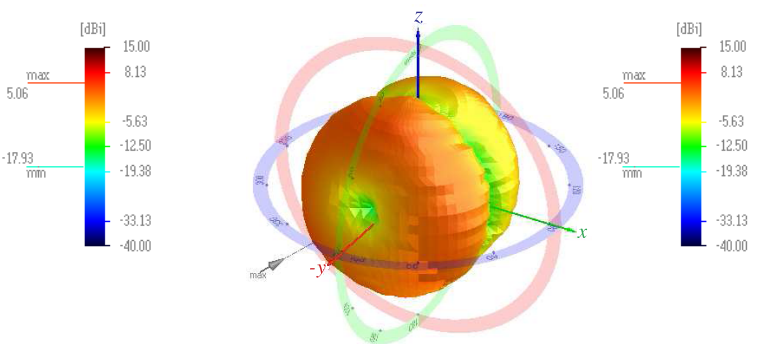

(d)

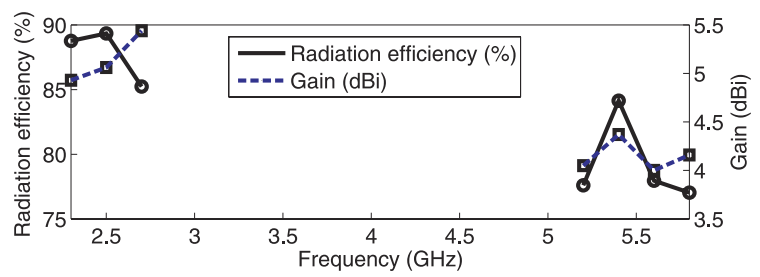

(e)

Fig. 3. (a) Photograph of the fabricated antenna with its case (b) measured and simulated return losses of the fabricated antenna (c) measured gain patterns at $2.5 \mathrm{GHz}(\mathrm{d})$ measured gain patterns at $5.5 \mathrm{GHz}$ (e) measured total efficiency and peak gain.

are $a=0.5 \mathrm{~mm}, b=5 \mathrm{~mm}, a^{\prime}=a-0.3 \mathrm{~mm}, b^{\prime}=b-0.15 \mathrm{~mm}, r=4.5 \mathrm{~mm}$, $r^{\prime}=r-0.5 \mathrm{~mm}$, and $\theta=77.4^{\circ}$. Other designed parameters are also shown in Fig. 1(c).

\section{Measured results}

The proposed antenna was etched on a $0.8 \mathrm{~mm}$-thick FR-4 substrate with a dielectric constant of 4.6 and a tangent loss value of 0.025 . Direct antenna feeding was conducted using $50-\Omega$ semi-flexible coaxial cable at the feeding point (between the ground plane and the circular hook-shaped patch). The etched antenna with a USB connecting port was also fabricated into a plastic case, as shown in Fig. 3(a), to test the reflection and radiation performance levels in an RF anechoic chamber. Fig. 3(b) depicts the simulated and measured return losses of the fabricated antenna. The measured result is in 
good agreement with the result simulated using Ansoft HFSS. It was also noted that the proposed antenna exhibits two broadband resonances (2.29$2.98 \mathrm{GHz}$ and $5.12-6.35 \mathrm{GHz}$ ), which support pentaband wireless services that include the WiBro $(2.3-2.4 \mathrm{GHz})$, Bluetooth $(2.4-2.484 \mathrm{GHz}), 2.5 \mathrm{GHz}$ WiMAX (2.5-2.7 GHZ), S-DMB (2.605-2.655 GHz) and 802.11 b/g/a WLAN $(2.4-2.485 \mathrm{GHz}$ and $5.15-5.825 \mathrm{GHz})$ bands. Figs. 3(c) and 3(d) illustrate the measured three-dimensional gain patterns of the proposed antenna at $2.5 \mathrm{GHz}$ and $5.5 \mathrm{GHz}$, respectively. These figures show that the measured patterns both at $2.5 \mathrm{GHz}$ and $5.5 \mathrm{GHz}$ are nearly omni-directional. Furthermore, the radiation pattern at $2.5 \mathrm{GHz}$ is similar to that of a half-wavelength dipole antenna. The measured data for the peak gain and total radiation efficiency of the fabricated antenna are represented in Fig. 3(e). The realized peak gain is about $4.93-5.44 \mathrm{dBi}$ in the lower resonant band and $4.05-4.37 \mathrm{dBi}$ in the upper resonant band. The minimum efficiency was $77 \%$ at $5.8 \mathrm{GHz}$.

\section{Conclusion}

A dual-wideband planar antenna consisting of a circular hook-shaped patch and a monopole stub is proposed here for wireless USB dongle applications. An optimum design for WiBro/Bluetooth/WLAN/WiMAX/S-DMB operation was performed and tested. The implemented antenna exhibits a reasonable level of antenna gain and an omni-directional radiation pattern. In addition, the radiating element occupies only a small dimension of $10 \times 9.5 \mathrm{~mm}^{2}$. Therefore, the antenna is suitable for use in compact, multiband wireless USB dongle devices.

\section{Acknowledgments}

This research was supported by Basic Science Research Program through the National Research Foundation of Korea (NRF) funded by the Ministry of Education, Science and Technology (2010-0004088) 